\title{
Linkage analysis in Rett syndrome families suggests that there may be a critical region at $\mathrm{Xq} 28$
}

\author{
T Webb, A Clarke, F Hanefeld, J-L Pereira, L Rosenbloom, C G Woods
}

Department of Clinical Genetics, Birmingham Maternity Hospital, Birmingham B15 2TG, UK

$\mathrm{T}$ Webb

Institute of Medical Genetics, University Hospital of Wales, Heath Park, Cardiff CF4 4XW, UK

A Clarke

Department of

Paediatrics and Child Neurology, University of Gottingen,

Gottingen, Germany

F Hanefeld

Parana (Brazil) State General Hospital and Parana Rehabilitation Association, Avenue Iguacu 3983, Curitiba, Brazil

J-L Pereira

Child Development Centre, Alder Hey Children's Hospital, Eaton Road, Liverpool LI2 2AP, UK

L Rosenbloom

Department of Clinical Genetics, St James's University Hospital, Beckett Street, Leeds LS9 7TF, UK

C G Woods

Correspondence to: Dr Webb.

Received 19 February 1998 Revised version accepted for publication 3 June 1998

\begin{abstract}
A whole $X$ chromosome study of families in which Rett syndrome had been diagnosed in more than one member indicated that the region between Xq27 and Xqter was the most likely region to harbour a gene which may be involved in the aetiology of the disease. Further, more detailed studies of Xq28 detected weak linkage and a higher than expected sharing of maternally inherited alleles. It is suggested that there may be more than one gene involved in the aetiology of this syndrome, particularly as the very rare families in which more than one girl is affected often show variable clinical symptoms.
\end{abstract}

( $F$ Med Genet 1998;35:997-1003)

Keywords: Rett syndrome; linkage analysis; Xq28

Rett syndrome is a severe progressive neurodegenerative disease which appears to affect females only. ${ }^{1}$ It is characterised by apparently normal development for the first 6-18 months of life followed by a marked deterioration. Not only do the affected girls fail to continue to develop normally but they lose skills already acquired such as purposeful hand movement. The syndrome finally leads to severe mental handicap with acquired microcephaly, dementia, autistic behaviour, gait apraxia, and stereotypic hand movements. ${ }^{2}{ }^{3}$ Diagnosis is always made from clinical signs and symptoms as there is no known biochemical, cytogenetic, or molecular marker associated with the syndrome. If such a marker were to become available it would not only aid in the differential diagnosis of this syndrome, which despite its severity has many variants including forme fruste, ${ }^{4}$ but would also further our understanding of the neuropathological deterioration of brain function which is so characteristic of this disease.

Genetic studies are handicapped by the absence of familial cases of Rett syndrome. Despite the relative prevalence, which has been estimated at about 1 in $10000-1$ in 15000 girls, ${ }^{56}$ more than $95 \%$ of cases are sporadic. This has led to the suggestion that the cause is an $\mathrm{X}$ linked dominant condition which is lethal in males with almost every case being the result of a new mutation. Familial cases have occasionally been reported, there is concordance in monozygotic twins and discordance in dizygotic twins, and geneological data from Sweden suggest a genetic if complex aetiology.
In familial cases where the affected girls are half sisters or where an affected girl has an aunt who has forme fruste, inheritance is always through the maternal line. There has even been one case of direct transmission from an affected mother to her affected daughter. ${ }^{8}$

Two reports of girls with Rett syndrome and chromosome translocations involving the short arm of the $\mathrm{X}$ chromosome, $\mathrm{Xp}$, raised the possibility of localising an $\mathrm{X}$ linked disease gene. ${ }^{9-11}$ Disappointingly the breakpoints in the two translocations (one in Xp11.22 and the other in Xp22.11, later revised to Xp21.3) proved to be very far apart with no inversion or deletion of intervening $\mathrm{X}$ chromosome material.

Studies aimed at detecting possible disomy of the $\mathrm{X}$ chromosome have proved negative ${ }^{1213}$ and those detecting skewing of $\mathrm{X}$ inactivation have proved inconclusive. Although skewing has been observed in girls with Rett syndrome and it has invariably favoured the preferential inactivation of the paternally inherited $\mathrm{X}$ chromosome, ${ }^{13} 14$ it occurs only occasionally and is not particularly marked.

The paucity of familial cases of Rett syndrome has limited molecular genetic investigations to searching for regions of the $\mathrm{X}$ chromosome where affected family members share maternally inherited alleles. This approach has been taken by various authors ${ }^{15-18}$ who have excluded much of the $\mathrm{X}$ chromosome as a potential site for a Rett syndrome gene. Taken together, these studies indicated that the centromeric region of the $\mathrm{X}$ chromosome lying between $\mathrm{Xp} 21$ and Xq25 is unlikely to contain a gene for Rett syndrome. Unfortunately, this excludes both of the breakpoints involved in the two short arm translocations previously reported in Rett syndrome girls. ${ }^{11}$ The telomeric regions between Xp21-Xpter and Xq25-Xqter remained as candidate regions until a recent paper from Xiang et $a l^{19}$ suggested that telomeric $\mathrm{Xq}$ was the more likely.

The availability of DNA samples from a small series of families with more than one female with Rett syndrome prompted an investigation of loci on the $\mathrm{X}$ chromosome in an attempt to clarify the mode of inheritance and to determine whether there is a likely candidate region.

\section{Methods}

Studies were carried out on genomic DNA obtained from members of six families in which more than one female had been diagnosed with 
Table 1 Markers on the X chromosome used in the study of Rett syndrome with published distances from Xpter

\begin{tabular}{|c|c|c|c|c|c|c|}
\hline Locus & $\begin{array}{l}\text { Wang et } \\
a l^{22}(M b)\end{array}$ & $\begin{array}{l}\text { Poutska et } \\
a l^{21}(M b)\end{array}$ & $\begin{array}{l}\text { Wang et } a l^{22} \\
(c M)\end{array}$ & $\begin{array}{l}\text { Fain et } \\
a l^{l^{4}}(c M)\end{array}$ & $\begin{array}{l}\text { Gyapay et } \\
a l^{20}(c M)\end{array}$ & $\begin{array}{l}\text { Donnelly et } \\
\left.a l^{23}(c M)\right)\end{array}$ \\
\hline DXS996 & 3.1 & 5.5 & 20.3 & 11.7 & 5 & 27.2 \\
\hline KAL & 7.9 & 9 & & 16.0 & & \\
\hline DXS987 & & 17 & & & 19 & 49.2 \\
\hline DXS997 & 29.8 & 35 & 58.8 & 50.1 & 44 & 80.0 \\
\hline DXS538 & 31.4 & & 69.4 & 58.0 & & 89.1 \\
\hline DXS1068 & 32.2 & 41 & 70.5 & 61.8 & 53 & 90.7 \\
\hline \multicolumn{7}{|l|}{ DXS7125 } \\
\hline DXS7 & 44.0 & 44 & 83.3 & & & 101.7 \\
\hline ARAF1 & 47.7 & 48 & & & & \\
\hline PFC & 49.6 & 42.5 & 95.3 & 82.8 & & 114.8 \\
\hline DXS991 & 54.4 & 56 & 98.6 & & 85 & 117.0 \\
\hline DXS1000 & 55.1 & 54 & 94.4 & 84.2 & 85 & 123.4 \\
\hline \multicolumn{7}{|l|}{ DXS573 } \\
\hline ALAS-2 & 56.8 & 55 & & & & 120.6 \\
\hline AR & 68.4 & 64 & 101.6 & 87.4 & & 121.0 \\
\hline DXS983 & & & & & 91 & \\
\hline \multicolumn{7}{|l|}{ DXS1111 } \\
\hline DXS453 & 72.9 & 69 & 106.9 & 93.6 & & 127.9 \\
\hline DXS559 & 74.9 & & & & & \\
\hline DXS441 & 83.4 & 76 & 108.3 & 96.0 & & \\
\hline DXS995 & 92.3 & 83 & 108.5 & 96.0 & 94 & \\
\hline DXS738 & & & & & 95 & \\
\hline DXS1002 & 92.3 & & 108.5 & & & \\
\hline DXS986 & 92.6 & 74 & 108.6 & 96.0 & 95 & 130.8 \\
\hline DXS990 & 99.0 & & & & 102 & \\
\hline DXS458 & 100.7 & 96 & 120.4 & 107.4 & & 144.9 \\
\hline DXS454 & 101.1 & 100 & 121.1 & 109.9 & & 147.8 \\
\hline DXS1105 & 117.6 & & 128.0 & & & \\
\hline DXS571 & & 109.5 & & & & \\
\hline Col4A5 & 117.6 & & 127.7 & & & 108.5 \\
\hline DXS1001 & 129.4 & & 148.3 & & 124 & \\
\hline DXS424 & 129.5 & 118 & 136.7 & 126.2 & & 167.8 \\
\hline DXS1106 & 137.4 & 104 & 132.9 & 109.9 & 137 & \\
\hline DXS994 & 144.8 & 120 & 162.3 & 147 & 137 & 191.3 \\
\hline DXS984 & 148.8 & 140.5 & 167.6 & 152.8 & 143 & 199.4 \\
\hline DXS998 & 152.8 & 151 & 191.5 & 175.1 & 160 & 222.4 \\
\hline F8 & 163.0 & 158.5 & 206.6 & 187.9 & & 234.7 \\
\hline
\end{tabular}

Rett syndrome. In all, 30 family members were studied of whom 13 were affected. In family 1 an affected aunt-niece pair is related through the female line, in families $3,4,5$, and 6 there are two affected sisters, while in family 2 there are three affected sisters and one normal girl.

Family name : Rett1

\begin{tabular}{|ll|}
\hline Markers & Alleles \\
994 & $1,2,3$ \\
984 & $1,2,3$ \\
998 & $1,2,3$ \\
AC-2 & 1,2 \\
731 & $1,2,3$ \\
1691 & $1,2,3$ \\
1123 & $1,2,3$ \\
7423 & $1,2,3$ \\
p26 & $1,2,3$ \\
p39 & $1,2,3$ \\
F8 & $1,2,3$ \\
F822 & $1,2,3$ \\
S1108 & $1,2,3,4$ \\
S154 & $1,2,3$ \\
\hline
\end{tabular}

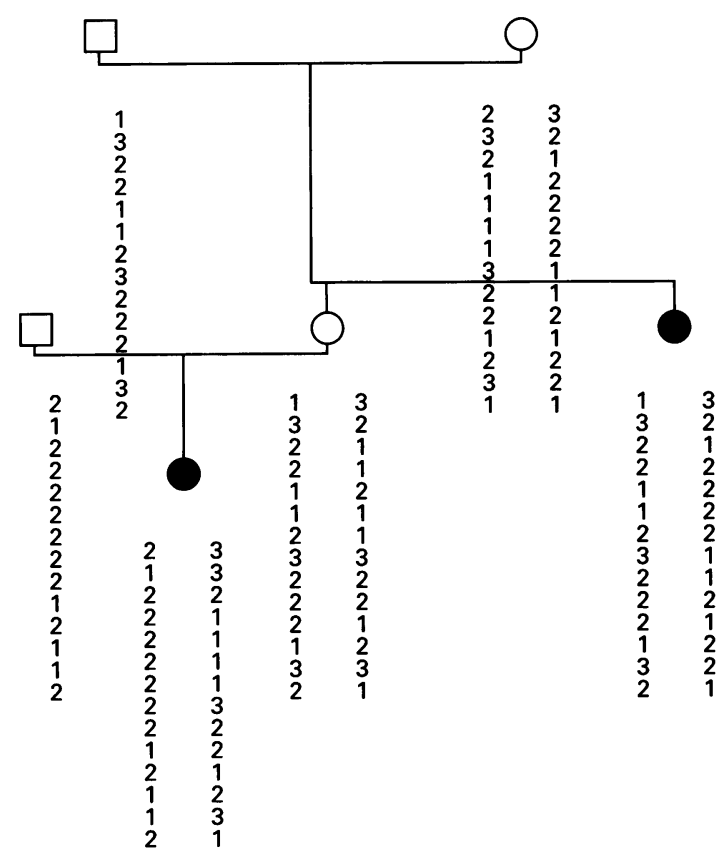

Figure 1 Pedigree of family 1.
Firstly, microsatellite analysis was performed using a series of markers chosen for even coverage of the whole of the $\mathrm{X}$ chromosome. Initial screening was undertaken using a set of primers available from Research Genetics Inc, as data concerning their location within the $\mathrm{X}$ chromosome could be obtained from the Genethon map. ${ }^{20}$ Over time, further markers were used, either to fill in the gaps where coverage was less dense or where the markers proved to be uninformative in the families, or to investigate further regions of interest. For these latter markers, data were obtained from published sequences and the primers purchased from Life Sciences Technology. In this part of the study 37 loci were investigated with an average distance between them of about 4 $\mathrm{cM}$.

Microsatellites were assayed by standard methods in a final volume of $5 \mu \mathrm{l}$ which contained approximately $20 \mathrm{ng}$ of genomic DNA. Cycling conditions were assessed for each individal primer pair and in order to conserve DNA, where annealing temperature and product size permitted, they were used in multiplex reactions. Products were resolved on $6 \%$ acrylamide gels and visualised by Kodak T-mat L/RA film for between 3 and 72 hours according to reaction efficiency.

The position of each locus and the distances between them were compiled from published maps. ${ }^{20-24}$ Although estimates of interlocus distances, both physical $(\mathrm{Mb})$ and genetic $(\mathrm{cM})$, did vary between the different sources there were very few discrepancies in the ordering of loci (table 1).

After the initial screening of the $\mathrm{X}$ chromosome it was decided to investigate the Xq27-28 region in greater depth. Primers were selected with an average heterozygosity of $>70 \%$ aimed at covering the Xq27-28 region of about $10 \mathrm{Mb}$ at an average spacing of about $1 \mathrm{Mb}$. Primer sequences were obtained from published linkage studies of other loci in Xq28 and, where necessary, manufactured by Life Sciences Technology. PCR amplification was carried out according to the published protocols in the original studies and the products separated on $6 \%$ acrylamide gels. Autoradiography took between 3 and 72 hours.

\section{Results}

The pedigrees of the families are shown in figs $1-6$. In fig 7 , the shaded areas indicate regions where affected family members share maternally inherited alleles at loci from the $\mathrm{X}$ chromosome. Columns 1, 2, and 3 depict sharing by the sister-sister pairs (II.2/II.3, II.2/II.4, and II.3/II.4) from family 2 and columns 4, 5, and 6 show sharing of maternal alleles by three sister-sister pairs from families 3, 4, and 5, respectively. The last three columns show allele sharing between the unaffected sister from family 2 (II.1) and each of her three affected sisters (II.2, II.3, and II.4). In these columns the shaded areas correspond to regions of nonconcordant inheritance of maternal alleles between the affected girls and their normal sister. It can be seen that there is no region of the $\mathrm{X}$ chromosome between DXS996 (in Xp22) 
Family name : Rett2

\begin{tabular}{|ll|}
\hline Markers & Alleles \\
994 & $1,2,3$ \\
984 & $1,2,3$ \\
998 & $1,2,3$ \\
AC-2 & 1,2 \\
731 & $1,2,3$ \\
1691 & $1,2,3$ \\
1123 & $1,2,3$ \\
7423 & $1,2,3$ \\
p26 & $1,2,3$ \\
P39 & $1,2,3$ \\
F8 & $1,2,3$ \\
F822 & $1,2,3$ \\
S1108 & $1,2,3,4$ \\
S154 & $1,2,3$ \\
\hline
\end{tabular}

$$
\begin{array}{ll}
2 & 1 \\
1 & 2 \\
1 & 3 \\
2 & 1 \\
2 & 1 \\
2 & 2 \\
1 & 2 \\
2 & 1 \\
3 & 1 \\
3 & 2 \\
1 & 3 \\
2 & 2 \\
3 & 2 \\
1 & 2
\end{array}
$$

Figure 2 Pedigree of family 2.

and DXS1106 (in Xq26) where affected family members all share maternally inherited alleles. However, distal to Xq26 an increased level of allele sharing was detected prompting further

Family name : Rett3

\begin{tabular}{|ll|}
\hline Markers & Alleles \\
994 & $1,2,3$ \\
984 & $1,2,3$ \\
998 & $1,2,3$ \\
AC-2 & 1,2 \\
731 & $1,2,3$ \\
1691 & $1,2,3$ \\
1123 & $1,2,3$ \\
7423 & $1,2,3$ \\
p26 & $1,2,3$ \\
p39 & $1,2,3$ \\
F8 & $1,2,3$ \\
F822 & $1,2,3$ \\
S1108 & $1,2,3,4$ \\
S154 & $1,2,3$ \\
\hline
\end{tabular}

Figure 3 Pedigree of family 3.

Table 2 Markers in Xq28 used in the study of Rett syndrome

\begin{tabular}{lllll}
\hline Locus & $\begin{array}{l}\text { Distance from Xpter in } \\
M b\left(\text { Nelson } \text { et }^{25} \text { ) }\right.\end{array}$ & $\begin{array}{l}\text { Distance from Xpter in } \\
\left.c M \text { (Fain et al }{ }^{4}\right)\end{array}$ & Position & Reference \\
\hline DXS998 & 150 & 175.1 & Xq27.3 & 31 \\
AC-2 & 151.5 & 175.7 & Xq27.3 & 32 \\
DXS731 & & 176.3 & Xq28 & 33 \\
DXS1691 & 152.1 & & Xq28 & 34 \\
DXS1123 & 152.8 & 177.0 & Xq28 & 23 \\
DXS7423 & 154.28 & & Xq28 & 35 \\
p26 & 156.7 & & Xq28 & 36 \\
p39 & 156.7 & 187.0 & Xq28 & 36 \\
F8int13 & 158.9 & & Xq28 & 37 \\
F8int22 & & 190.0 & Xq28 & 38 \\
DXS1108 & 159.8 & & Xq28 & 27 \\
DXYS154 & 159.9 & & Xq28-qter & 27 \\
\hline
\end{tabular}

investigation of the $\mathrm{Xq} 27-28$ region. The increased level of sharing detected at DXS994, DXS984, DXS998, and F8 is illustrated in fig 8.

For distal Xq, further loci were studied with intermarker distances of between 0.1 and about $2 \mathrm{Mb}$. The relative positions of the marker loci and the distances between them were obtained from Fain $e t a l^{24}$ and Nelson et $a l^{55}$ and are shown in table 2.

\section{LINKAGE ANALYSIS}

As only a few families were available for study, in order to see whether X linkage is in fact likely, two point analysis was performed between the disease and each locus in turn using the programme LIPED. ${ }^{26}$ The syndrome was assumed to be fully penetrant and to have a gene frequency of 0.0001 . The lod scores are shown in tables 3 and 4.

Haplotype construction was carried out using Cyrillic version 2.0. The maximum lod scores obtained for each locus and the approximate distances between them are shown in table 3. A further seven loci studied are not shown as more than one family was found to be uninformative. In one family in particular, the mother was often homozygous.

Inspection of table 3 shows that the lod scores are negative throughout almost the whole of the $\mathrm{X}$ chromosome. Weakly positive scores were observed in four places, around DXS987-DXS538 in Xp22, between DXS7 and ARAF1 in Xp11, between DXS1111 and DXS559 in Xq12, and at the Xq telomeric region. The most positive scores were for DXS994 and F8 where $Z=1.502$ at $\theta=0.001$ (table 3).

In Xq28 a positive lod score was obtained at each of the loci tested with the exception of DXS1691. At this locus, however, family 2 was uninformative so there were correspondingly fewer meioses. The highest lod score obtained was at DXYS154 where $Z \max =1.935$ at $\theta=0$. 
Table 3 Lod scores for $X$ linked loci obtained for families with Rett syndrome

\begin{tabular}{|c|c|c|c|c|c|c|c|c|c|}
\hline Locus & $M b$ & 0.001 & 0.05 & 0.1 & 0.2 & 0.3 & 0.4 & $Z \max$ & $\theta$ \\
\hline DXS996 & 3.1 & -4.496 & -1.184 & -0.673 & -0.254 & -0.088 & -0.019 & -0.019 & 0.4 \\
\hline KAL & 4.8 & -4.796 & -1.442 & -0.888 & -0.388 & -0.152 & -0.036 & -0.036 & 0.4 \\
\hline DXS987 & 8.0 & -6.594 & -1.626 & -0.861 & -0.244 & -0.018 & 0.042 & 0.042 & 0.4 \\
\hline DXS997 & 1.6 & -2.398 & -0.721 & -0.444 & -0.194 & -0.076 & -0.018 & -0.018 & 0.4 \\
\hline DXS538 & 13.9 & -6.833 & -1.884 & -1.077 & -0.378 & -0.082 & 0.025 & 0.025 & 0.4 \\
\hline DXS1068 & 0.8 & -2.398 & -0.721 & -0.444 & -0.194 & -0.076 & -0.018 & -0.018 & 0.4 \\
\hline DXS7125 & & -2.098 & -0.463 & -0.229 & -0.060 & -0.012 & -0.001 & -0.001 & 0.4 \\
\hline DXS7 & 7.8 & -1.797 & -0.185 & 0.026 & 0.144 & 0.135 & 0.078 & 0.144 & 0.2 \\
\hline ARAF1 & 3.7 & -1.798 & -0.205 & -0.014 & 0.074 & 0.052 & 0.016 & 0.074 & 0.2 \\
\hline PFC & 1.9 & -4.496 & -1.184 & -0.673 & -0.254 & -0.088 & -0.019 & -0.019 & 0.4 \\
\hline DXS991 & 4.8 & -4.796 & -1.442 & -0.888 & -0.388 & -0.152 & -0.036 & -0.036 & 0.4 \\
\hline DXS988 & 2 & -2.398 & -0.721 & -0.444 & -0.194 & -0.076 & -0.018 & -0.018 & 0.4 \\
\hline DXS1000 & 1.1 & -2.098 & -0.463 & -0.229 & -0.06 & -0.012 & -0.001 & -0.001 & 0.4 \\
\hline DXS573 & & -4.496 & -1.184 & -0.673 & -0.254 & -0.088 & -0.019 & -0.019 & 0.4 \\
\hline ALAS-2 & 2.4 & -9.417 & -2.905 & -1.816 & -0.846 & -0.386 & -0.134 & -0.134 & 0.4 \\
\hline $\mathrm{AR}$ & 11.6 & -7.019 & -2.184 & -1.372 & -0.652 & -0.31 & -0.116 & -0.116 & 0.4 \\
\hline DXS1111 & & -1.497 & 0.073 & 0.245 & 0.278 & 0.198 & 0.095 & 0.278 & 0.2 \\
\hline DXS453 & 4.5 & -6.594 & -1.626 & -0.861 & -0.244 & -0.018 & 0.042 & 0.042 & 0.4 \\
\hline DXS559 & 2.0 & -3.895 & -0.66 & -0.203 & 0.084 & 0.123 & 0.077 & 0.123 & 0.3 \\
\hline DXS441 & 8.5 & -4.496 & -1.184 & -0.673 & -0.254 & -0.088 & -0.019 & -0.019 & 0.4 \\
\hline DXS995 & 8.9 & -2.098 & -0.463 & -0.229 & -0.06 & -0.012 & -0.001 & -0.001 & 0.4 \\
\hline DXS738 & & -4.797 & -1.463 & -0.928 & -0.458 & -0.234 & -0.097 & -0.097 & 0.4 \\
\hline DXS1002 & 0 & -4.496 & -1.191 & -0.686 & -0.276 & -0.113 & -0.038 & -0.038 & 0.4 \\
\hline DXS986 & 0.3 & -6.894 & -1.926 & -1.157 & -0.518 & -0.245 & -0.099 & -0.099 & 0.4 \\
\hline DXS990 & 6.4 & -4.496 & -1.184 & -0.673 & -0.254 & -0.088 & -0.019 & -0.019 & 0.4 \\
\hline DXS458 & 1.7 & -9.893 & -3.113 & -2.031 & -0.980 & -0.450 & -0.151 & -0.151 & 0.4 \\
\hline DXS454 & 0.4 & -4.496 & -1.184 & -0.673 & -0.254 & -0.088 & -0.019 & -0.019 & 0.4 \\
\hline Col4A5 & 9.5 & -4.796 & -1.462 & -0.888 & -0.388 & -0.152 & -0.036 & -0.036 & 0.4 \\
\hline DXS1105 & & -7.195 & -2.184 & -1.372 & -0.652 & -0.309 & -0.116 & -0.116 & 0.4 \\
\hline DXS571 & 1 & -7.195 & -2.184 & -1.372 & -0.652 & -0.309 & -0.116 & -0.116 & 0.4 \\
\hline DXS1001 & 7.0 & -3.896 & -0.647 & -0.202 & 0.084 & 0.122 & 0.077 & 0.122 & 0.3 \\
\hline DXS424 & 11.9 & -4.196 & -0.926 & -0.458 & -0.12 & -0.024 & -0.002 & -0.002 & 0.4 \\
\hline DXS1106 & 7.9 & -4.496 & -1.184 & -0.673 & -0.254 & -0.088 & -0.019 & -0.019 & 0.4 \\
\hline DXS994 & 7.4 & 1.502 & 1.329 & 1.15 & 0.79 & 0.445 & 0.162 & 1.502 & 0.001 \\
\hline DXS984 & 4.0 & -6.894 & -2.605 & -1.114 & -0.437 & -0.175 & -0.052 & -0.052 & 0.4 \\
\hline DXS998 & 4.0 & -1.498 & 0.051 & 0.196 & 0.188 & 0.077 & 0.014 & 0.196 & 0.1 \\
\hline F8 & 9.2 & 1.502 & 1.330 & 1.150 & 0.790 & 0.444 & 0.162 & 1.502 & 0.001 \\
\hline
\end{tabular}

Figures in the column marked $\mathrm{Mb}$ refer to interlocus distances.

ALLELE SHARING

As there are no three generation families in which to conduct linkage studies and the mode of inheritance is still unknown, investigations have concentrated on the production of exclusion maps derived from the sharing of maternally inherited alleles on the $\mathrm{X}$ chromosome. In this study, sharing of informative maternal alleles by affected sibs indicates that only Xq27-28 cannot be excluded as a potential site for a Rett syndrome gene (figs 7 and 8 ). In family 2 , there is no concordance between the three affected sisters from Xpter until DXS994. In family 3, the two affected girls show discordance from Xpter to Xp11 but are concordant thereafter at 21 informative loci. In contrast, family 4 showed concordance at $\mathrm{Xp} 22$ but then the sisters did not inherit the same maternal allele at informative loci until DXS1001 in Xq24. Although a double crossover is always a possibility, there were 17 loci studied between these points with an average spacing of only 7 $\mathrm{Mb}$.

ALLELE SHARING AT LOCI IN THE Xq27-28 REGION Family 1 (fig 1)

In family 1 , the mother of the proband and her affected sister share maternal alleles at DXS998 and DXS731, but then a recombination event means that they have inherited different alleles at DXS1691, DXS7423, DXS1123, and p26. Distal to p26 the grandmother is homozygous and hence uninformative until DXS1108 is reached, where her two daughters are again discordant. At DXYS154, the grandmother is once again homozygous. Thus, the affected girl and her aunt may not have much of the $\mathrm{Xq} 28$ region in common. Even where the aunt and her sister (the mother of the proband) do share grandmaternal alleles, that is, at DXS998 and DXS731, the proband

Table 4 Lod scores for loci at Xq28 in families with Rett syndrome

\begin{tabular}{|c|c|c|c|c|c|c|c|c|}
\hline \multirow[b]{2}{*}{ Locus } & \multicolumn{6}{|c|}{ Lod score $\theta$} & \multirow[b]{2}{*}{$Z \max$} & \multirow[b]{2}{*}{$\theta$} \\
\hline & 0.001 & 0.05 & 0.1 & 0.2 & 0.3 & 0.4 & & \\
\hline DXS998 & -1.498 & 0.051 & 0.196 & 0.188 & 0.077 & -0.014 & 0.196 & 0.1 \\
\hline AC-2 & 1.202 & 1.072 & 0.935 & 0.656 & 0.380 & 0.135 & 1.202 & 0.001 \\
\hline DXS731 & -1.198 & 0.309 & 0.411 & 0.322 & 0.141 & 0.003 & 0.411 & 0.1 \\
\hline DXS1691 & -4.136 & -0.926 & -0.458 & -0.06 & -0.012 & -0.024 & -0.012 & 0.3 \\
\hline DXS1123 & -2.995 & 0.146 & 0.478 & 0.536 & 0.356 & 0.03 & 0.536 & 0.2 \\
\hline DXS7423 & -1.198 & 0.309 & 0.454 & 0.392 & 0.222 & 0.065 & 0.454 & 0.1 \\
\hline p26 & -3.895 & -0.649 & -0.208 & -0.064 & 0.082 & 0.03 & 0.082 & 0.3 \\
\hline p39 & 0.901 & 0.793 & 0.68 & 0.452 & 0.234 & 0.066 & 0.901 & 0.001 \\
\hline F8int 13 & 1.502 & 1.330 & 1.150 & 0.790 & 0.444 & 0.162 & 1.502 & 0.001 \\
\hline F8int22 & 1.502 & 1.330 & 1.15 & 0.79 & 0.44 & 0.162 & 1.502 & 0.001 \\
\hline DXS1108 & -3.295 & -0.246 & 0.007 & 0.198 & 0.146 & 0.047 & 0.198 & 0.2 \\
\hline DXYS154 & 1.686 & 1.645 & 1.365 & 0.852 & 0.421 & 0.117 & 1.686 & 0.001 \\
\hline
\end{tabular}


Family name : Rett4

\begin{tabular}{|ll|}
\hline Markers & Alleles \\
994 & $1,2,3$ \\
984 & $1,2,3$ \\
998 & $1,2,3$ \\
AC-2 & $1,2,3$ \\
731 & $1,2,3$ \\
1691 & $1,2,3$ \\
1123 & $1,2,3$ \\
7423 & $1,2,3$ \\
p26 & $1,2,3$ \\
p39 & $1,2,3$ \\
F8 & $1,2,3$ \\
F822 & $1,2,3$ \\
S1108 & $1,2,3,4$ \\
S154 & $1,2,3$ \\
\hline
\end{tabular}

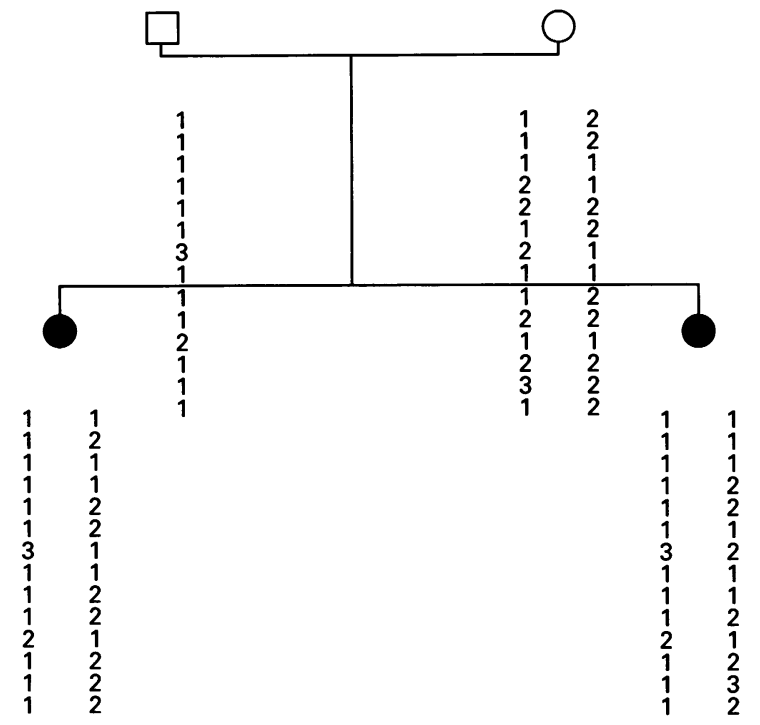

Figure 4 Pedigree of family 4.

Family name : Rett5

\begin{tabular}{|ll|}
\hline Markers & Alleles \\
994 & $1,2,3$ \\
998 & $1,2,3$ \\
AC-2 & $1,2,3$ \\
731 & $1,2,3$ \\
1691 & $1,2,3$ \\
1123 & $1,2,3$ \\
7423 & $1,2,3$ \\
p26 & $1,2,3$ \\
p39 & $1,2,3$ \\
F8 & $1,2,3$ \\
F822 & $1,2,3$ \\
S1108 & $1,2,3,4$ \\
S154 & $1,2,3$ \\
\hline
\end{tabular}

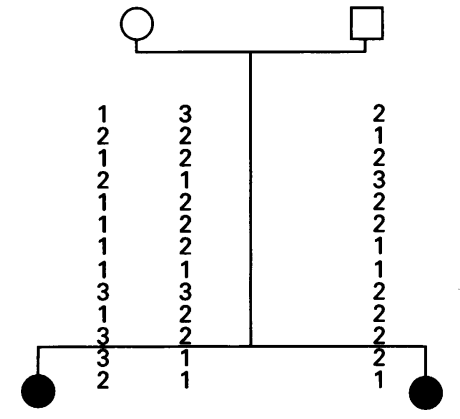

$\begin{array}{ll}1 & 2 \\ 2 & 1 \\ 1 & 2 \\ 2 & 3 \\ 1 & 2 \\ 1 & 2 \\ 1 & 1 \\ 1 & 1 \\ 3 & 2 \\ 1 & 2 \\ 3 & 2 \\ 3 & 2 \\ 2 & 1\end{array}$

$\begin{array}{ll}1 & 2 \\ 2 & 1 \\ 1 & 2 \\ 2 & 3 \\ 1 & 2 \\ 1 & 2 \\ 1 & 1 \\ 1 & 1 \\ 3 & 2 \\ 1 & 2 \\ 3 & 2 \\ 3 & 2 \\ 2 & 1\end{array}$

Figure 5 Pedigree of family 5.

has inherited grandpaternal alleles. These two loci are, however, at the Xq27-28 border, the most proximal part of the region studied, and are only $1 \mathrm{cM}$ apart. ${ }^{24}$ The grandmother is homozygous at five of the 12 loci investigated and her affected grandaughter appears to have inherited a grandmaternal $X$ chromosome from DXS1691-DXYS154 inclusive.

Family 2 (fig 2)

The three affected girls in this family share maternal alleles distributed throughout the whole of Xq28. Their unaffected sister has inherited the alternative maternal allele at all informative loci. No crossovers were observed within the region.
Family 3 (fig 3)

The two affected girls in this family also share maternally derived alleles throughout the entire Xq28 region from DXS998 through to and including DXYS154.

Family 4 (fig 4)

In contrast, the two affected sisters in this family are discordant for maternal alleles from DXS998 to DXS1108. Only DXS994 and near the telomere at DXYS154 do they appear to have inherited the same maternally derived allele. This implies that there has been a crossover between DXS1108 and DXYS154, which are only about $100 \mathrm{~kb}$ apart. Freije $e t ~ a l^{27}$ found one recombination event between these two loci in 238 informative female meioses. In this family, the mother is homozygous for six of the 12 loci studied and unfortunately the family was uninformative at both DXS998 and F8.

\section{Family 5 (fig 5)}

The two affected sisters in family 5 share the same maternal alleles from DXS994 in Xq27 through to and including DXYS154 in Xqter. Grandparental samples were obtained for this family, which showed that the maternally inherited Xq28 alleles present in the affected girls originated from the maternal grandmother. No crossovers were observed within the region in this family.

\section{Family 6 (fig 6)}

The two affected sisters in this family have again inherited the same maternal allele at all informative loci in Xq28 from DXS731 to DXYS154.

Simple $\chi^{2}$ calculations of observed versus expected sharing of alleles according to the method of $\mathrm{Ott}^{26}$ indicate that in these six families there is significant sharing by affected sib pairs above that expected: at $F 8, p=0.025$ and at DXYS154, $0.01>\mathrm{p}>0.005$.

\section{Discussion}

A study of six families with more than a single female affected with Rett syndrome has shown weak linkage to loci in Xq28 with a maximum lod score of 1.935 at $\theta=0$ at DXYS154 located close to the Xq telomere. The lod score does not quite reach 2.0, which is the accepted level at which linkage is felt to be shown, but a positive score was obtained at 11 of 12 loci investigated (table 4). At DXS1691, the only locus with a negative score, the mother of family 2 is uninformative. This family has had the greatest effect on the results of this study, as not only are there three affected sisters but this is the only family with an unaffected sister also.

Previous to this study and that of Xiang et $a l,{ }^{19} \mathrm{sib}$ pair analysis of shared alleles in Xq28 had been investigated in three families. In one of these families (RS3), affected half sisters shared maternal alleles at DXS15 and DXS134 ${ }^{16}$ and also at GABRA3, DXS13, and DXS52 ${ }^{17}$ In a second family (RS1), full sisters showed concordance at DXS52 and F8, ${ }^{18}$ while in the third family Ellison $e t a l^{17}$ showed that a second pair of half sisters shared maternal alleles at GABRA3 and DXS13, while DXS52 was 
Family name : Rett6

\begin{tabular}{|ll|}
\hline Markers & Alleles \\
DXS458 & $1,2,3,4$ \\
731 & $1,2,3$ \\
1691 & $1,2,3$ \\
1123 & $1,2,3$ \\
7423 & $1,2,3$ \\
F822 & $1,2,3$ \\
S1108 & $1,2,3,4$ \\
S154 & $1,2,3$ \\
\hline
\end{tabular}
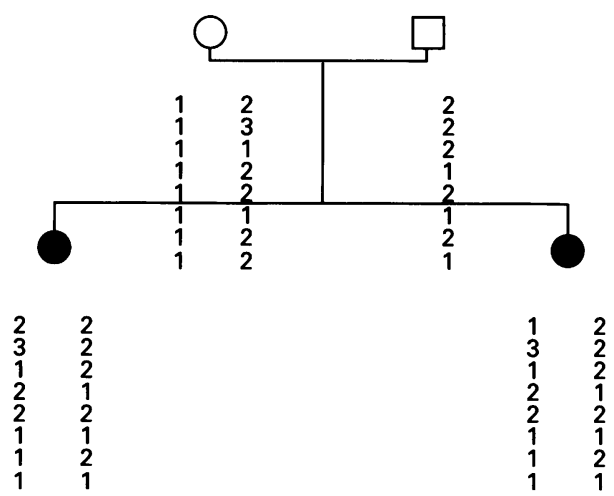

Figure 6 Pedigree of family 6.

Family 2

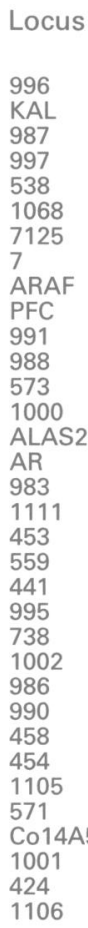

Figure 7 Allele sharing at loci on the $X$ chromosome between pairs of sibs from families in which Rett syndrome is segregating. Shaded areas denote regions of sharing of maternally inherited alleles in affected sib pairs and discordant sharing between an affected girl and the unaffected sister from family 2.

Sib pair

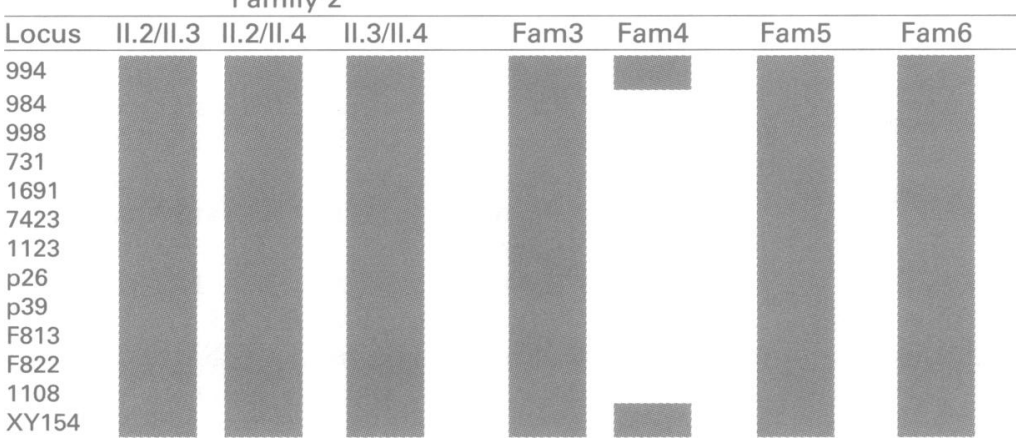

Figure 8 Allele sharing at loci in Xq27-28 between pairs of sibs affected with Rett syndrome. Shaded areas denote shared maternally inherited regions. uninformative. None of these studies detected any discordant inheritance of maternal alleles from Xq28 in affected sib pairs. Xiang et al ${ }^{19}$ recently investigated families with more than one affected female and concluded that the most likely region for a locus for Rett syndrome was distal Xq. Families 6, 7, and 9 in the study performed by Xiang et al ${ }^{19}$ correspond to families 3,4 , and 2 in this study, different markers were used, and the same conclusions reached independently.

$\mathrm{Xq27-28}$ is a very gene rich region and more than one syndrome with mental handicap and neurological signs and symptoms has already been identified within it. The gene for GABRA3, a member of the ubiquitous $\gamma$-aminobutyric acid neurotransmitter receptor family, is located in $\mathrm{Xq} 28,{ }^{28}$ as is L1CAM, the neural cell adhesion molecule L1. Specific mutations of the L1CAM gene are known to cause MASA syndrome, which is characterised by mental retardation, aphasia, and gait apraxia. ${ }^{29} \mathrm{~L} 1 \mathrm{CAM}$ is expressed in the brain of both children and adults and different gene mutations have been found to cause a wide variety of neurological symptoms. Both the GABRA3 and L1CAM genes must be considered to be strong candidates for involvement in any neurodegenerative disease found to be linked to $\mathrm{Xq} 28$. However, there have been some false reports of linkage of certain other conditions to the region ${ }^{30}$ and in this study the lod scores do not quite reach significance so these results must be interpreted with caution. An $\mathrm{X}$ chromosome wide linkage study found no evidence of a gene for Rett syndrome anywhere else on the $\mathrm{X}$ chromosome.

Searches for consistent cytogenetic abnormalities, disomy, or abnormalities of $\mathrm{X}$ inactivation have failed to detect any marked alteration in the behaviour of the $\mathrm{X}$ chromosome in Rett syndrome. This has led to the suggestion that the disease may not be $\mathrm{X}$ linked at all but is autosomal with sex limitation ${ }^{12}$ or that it is the result of a high level of germline mutation in the fathers. ${ }^{39}$ An alternative explanation for both the clinical and the molecular findings might be that there is not one single gene responsible for the syndrome but one or more autosomally located and one or more $\mathrm{X}$ linked. The presence of more than one predisposing gene would also help to explain the great preponderance of sporadic rather than familial cases. If there is an $\mathrm{X}$ linked gene involved in the aetiology, then it is most likely to lie in Xq28.

We would like to thank Dr G McCarthy for referring family 1 and Professor N Morton for reading the manuscript.

1 Rett A. Uber ein cerebral-atrophisches syndrom bei hyperammonamie. Vienna: Bruder Hollinek, 1966

2 Trevathan E, Naidu S. The clinical recognition and differential diagnosis of Rett syndrome. $\mathcal{F}$ Child Neurol Suppl 1988;3:506-15.

3 Clarke A. Rett syndrome. $\mathcal{F}$ Med Genet 1996;33:693-9.

4 Hagberg B, Gillberg C. Rett variants - Rettoid phenotypes In: Hagberg B, Anvret M, Wahlstrom J, eds. Rett syndrome clinical and biological aspects. Cambridge: Cambridge University Press, 1993:40-60.

5 Hagberg B. Rett syndrome: Swedish approach to analysis of prevalence and cause. Brain Dev 1985;7:277-80.

6 Kerr A, Stephenson JBP. Rett's syndrome in the west of Scotland. BMF 1985;291:579-82. 
7 Akesson HO, Hagberg B, Wahlstrom J. Rett syndrome, classical and atypical: genealogical support for common origin f Med Genet 1996;33:764-6.

8 Witt-Engerstrom I, Forslund $M$. Mother and daughter with Rett syndrome. Dev Med Child Neurol 1992;34:1022.

9 Journel H, Melki J, Turleau C, Munnich A, de Grouchy J. Rett phenotype with X/autosome translocation: possible mapping to the short arm of chromosome X. Am $\mathcal{F}$ Med mapping to the short

10 Zoghbi HY, Ledbetter DH, Schultz R, Percy AK, Glaze DG A de novo X;3 translocation in Rett syndrome. $A m \mathcal{F} M e d$

11 Ellison KA, Roth EJ, McCabe ERB, Chinault AC, Zoghbi HY. Isolation of a yeast artificial chromosome contig spanning the $\mathrm{X}$ chromosomal translocation breakpoint in a patient with Rett syndrome. Am $\mathcal{F}$ Med Genet 1993;47 1124-34

12 Migeon BR, Dunn MA, Thomas G, Schmeckpeper BJ, Naidu S. Studies of $\mathrm{X}$ inactivation and isodisomy in twins provide further evidence that the $\mathbf{X}$ chromosome is not involved in Rett syndrome. Am 7 Hum Genet 1995;56:647 53.

13 Webb T, Watkiss E. A comparative study of X-inactivation in Rett syndrome probands and control subjects. Clin Genet 1996;49:189-95

14 Camus P, Abbadi N, Perrier MC, Chery M, Gilgencrantz S. $\mathrm{X}$ chromosome inactivation in 30 girls with Rett syndrome. Hum Genet 1996;97:247-50.

15 Anvret M, Wahlstrom J, Skogsberg P, Hagberg B. Segregation analysis of the $\mathrm{X}$ chromosome in a family with Rett syndrome in two generations. Am F Med Genet 1990;37:31-

16 Archidiacono N, Lerone M, Rocchi M, et al. Rett syndrome: exclusion mapping following the hypothesis of germinal mosaicism for new X-linked mutations. Hum Genet 1991;86:604-6.

17 Ellison KA, Fill CP, Terwilliger J, et al. Examination of X chromosome markers in Rett syndrome: exclusion mapping with a novel variation on multilocus linkage analysis. Am f Hum Genet 1992;50:278-87.

18 Curtis ARJ, Headland S, Lindsay $S$, et al. $X$ chromosome linkage studies in familial Rett syndrome. Hum Genet linkage studies

19 Xiang F, Zhang Z, Clarke A, et al. Chromosome mapping of Rett syndrome: a likely candidate region on the telomere of Xq. F Med Genet 1998;35:297-300.

20 Gyapay G, Morissette J, Vignal A, et al. The 1993-1994 Genethon human genetic linkage map. Nat Genet 1994;7: 246-339.

21 Poutska AM, Schlessinger D. Fifth international workshop on X chromosome mapping 1994. Cytogenet Cell Genet 1994;67:295-358

22 Wang LH, Collins A, Lawrence S, Keats BJ, Morton NE. Integration of gene maps: chromosome X. Genomics 1994; 22:590-604.

23 Donnelly A, Kozman H, Gedeon AK, et al. A linkage map of microsatellite markers on the human $\mathrm{X}$ chromosome. Genomics 1994;20:363-70.
24 Fain PR, Kort EN, Chance PF, et al. A 2D crossover-based map of the human $\mathrm{X}$ chromosome as a model for map integration. Nat Genet 1995;9:261-6.

25 Nelson DL, Ballabio A, Cremers F, Monaco AP, Schlessinger $\mathrm{D}$. Report on the sixth international workshop on $\mathrm{X}$ chromosome mapping 1995. Cytogenet Cell Genet 1995;71: 308-42.

26 Ott J. Estimation of the recombination fraction in human pedigrees: efficient computation of the likelihood for human linkage studies. Am $\mathcal{H}$ Hum Genet 1974;26:588-97.

27 Freije D, Helms C, Watson MS, Donis-Keller H. Identification of a second pseudoautosomal region near the $\mathrm{Xq}$ and Yq telomeres. Science 1992;258:1784-7.

28 Schlessinger D, Little RD, Freije D, et al. Yeast artificia chromosome-based genome mapping: some lessons from Chromosome-based genome mappin

29 Kenwrick S, Jouet M, Donnai D. X linked hydrocephalus and MASA syndrome. $f$ Med Genet 1996;33:59-65.

30 Baron M, Freimer NF, Risch N, et al. Diminished suppor for linkage between manic depressive illness and $\mathrm{X}$-chromosome markers in three Israeli pedigrees. $\mathrm{Nat}$ Genet 1993;3:49-55.

31 Weissenbach J, Gyapay G, Dib C, et al. A second generation map of the human genome. Nature 1992;359:794-801.

32 Richards RI, Holman K, Kozman H, et al. Fragile X syndrome: genetic localisation by linkage mapping of two
microsatellite repeats FRAXAC1 and FRAXAC2 which microsatellite repeats FRAXAC1 and FRAXAC2 which immediate

33 Hudson T, Engelstein M, Matthias $\mathrm{KL}$, et al. Isolation and chromosomal assignment of 100 highly informative human simple sequence repeat polymorphisms. Genomics 1992;13 622-9.

34 Lindsay S, Splitt M, Edney S, et al. PPM-X: a new X-linked mental retardation syndrome with psychosis, pyramidal signs, and macroorchidism maps to Xq28. Am f Hum Genet signs, and macro

35 Laporte J, Hu LJ, Kretz C, et al. A gene mutated in X linked myotubular myopathy defines a new putative tyrosine phosphatase family conserved in yeast. Nat Genet 1996;13: 175-82.

36 Wehnert M, Reiner O, Caskey CT. Four STR polymorphisms map to a $500 \mathrm{~kb}$ region between DXS15 and DXS134. Hum Mol Genet 1993;2:1503.

37 Windsor S, Taylor SAM, Lillicrap D. Multiplex analysis of two intragenic microsatellite repeat polymorphisms in the genetic diagnosis of haemophilia $\mathrm{A} . \mathrm{Br} \mathcal{F}$ Haemato 994:86:810-15.

38 Lalloz MRA, McVey JH, Pattinson JK, Tuddenham EGD Haemophilia A diagnosis by analysis of a hypervariable dinucleotide repeat within the factor VIII gene. Lancet 1991;338:207-11.

39 Thomas GH. High male:female ratio of germ-line mutation an alternative explanation for postulated gestational lethality in males in X-linked dominant disorders. $A m \mathcal{F}$ Hum Genet 1996;58:1364-8. 